\title{
FOSTERING A GROWTH MIND-SET
}

\author{
INTEGRATING RESEARCH ON TEACHING \\ AND LEARNING AND THE PRACTICE OF TEACHING
}
Beth A. Fisher, Carolyn L. Dufault, Michelle D. Repice, Regina F. Frey
Washington University in St. Louis

Centers for teaching and learning have a crucial role to play in helping faculty learn about and apply research on learning. The approach we have developed integrates discussion of recent research with specific recommendations of teaching modifications that can be adapted for different disciplines and courses. Preliminary evaluation suggests the effectiveness of this approach in fostering a growth mind-set about teaching - a mind-set that helps faculty develop, implement, and assess effective teaching modifications, thereby transforming faculty into scholars of teaching and learning and further developing a collaborative, innovative culture that integrates research on teaching and learning with the practice of teaching.

O

Current interest in research on learning has opened up new avenues for improving teaching and learning in higher education. However, many faculty members have limited opportunities to learn about this research unless they are in fields such as cognitive science, neuroscience, education, or the learning sciences. Given their limited opportunities to learn about 
this research and consider how it might apply to their teaching, faculty often do not understand teaching and research on learning as mutually informing enterprises. Centers for teaching and learning have an essential and unique role to play in shifting the faculty mind-set about research on learning and its relation to their own developing pedagogical methods.

At the Teaching Center at Washington University, we have developed an integrative approach to working with faculty to develop, implement, and assess instructional modifications based on recent research on learning. Our approach integrates our expertise as experienced educators with research that is conducted in the learning sciences, discipline-specific educational research, and cognitive science. Our approach has these objectives:

o To help faculty develop and refine effective pedagogy

o To advance faculty knowledge of research on teaching and learning

- To advance faculty knowledge of how to incrementally incorporate instructional modifications that are informed by this research and adaptable for different disciplines

o To help faculty learn how to assess such modifications, either informally or in formal scholarship of teaching and learning (SoTL) projects

Preliminary evaluation using a faculty survey reveals enthusiasm about the potential of our approach to foster innovation in teaching and help faculty become scholars of teaching and learning.

Our approach builds on the work of scholars who have identified research-based principles that educators can use to improve instruction in higher education (Ambrose, Bridges, DiPietro, Lovett, \& Norman, 2010; Angelo, 1993) and in K-12 classrooms (Bransford, Brown, \& Cocking, 2000; Pashler et al., 2007). However, rather than presenting principles based on research, we select recent studies that are relevant to higher education teaching and then present details from the studies-including the methods and results-directly to faculty in our workshops, symposia, and consultations. This approach helps faculty develop a conceptual understanding of how researchers in various fields understand and measure learning. When faculty gain this conceptual understanding, they are better equipped to determine whether specific research findings can inform the design of pedagogical approaches in their own courses. This new understanding can also lead them to transform their knowledge of research on teaching and learning into what Bransford et al. (2000) describe as "useable knowledge"-knowledge that instructors can 
transfer, adapt, and modify as they work to improve and refine their teaching over time. In addition, learning about research on teaching and learning helps faculty make what can otherwise be a challenging leap-to become scholars of teaching and learning who understand research on learning and how it is conducted and are equipped to develop and assess instructional methods informed by this research, whether on their own or in consultation with teaching center staff.

Our approach has increased the number of faculty participating in our programs, including workshops, consultations, and iteach, a biennial teaching symposium. It has also helped faculty develop what William Buhro, professor and chairperson of chemistry, refers to as a "growth mind-set about teaching." Buhro has consulted extensively with the Teaching Center on the use of active learning and technology in his courses (Fisher, Miller, Buhro, Frank, \& Frey, 2012), and he has regularly attended our teaching symposium. The term growth mind-set is borrowed from Carol Dweck's (2006) concept of the distinction between "a growth versus a fixed mind-set." When asked to comment on the 2012 teaching symposium, Buhro noted:

I initially believed that one either had a knack for teaching, or sadly, did not. I believed that everything that could possibly be known about teaching had been discovered a long time ago, and endlessly discussed since. I have more recently developed a "growth mindset" about effective teaching, which I now see as the product of knowledge and skills developed over time. Participating in iteach and in the [Washington University] teaching community has fed that growth, giving me new insights into recent advances in research on cognition and learning - and new teaching methods that can be used to increase student motivation and learning in tough curricula. (personal communication, November 21, 2011; see also "2012 iteach," 2011)

Our approach to developing workshops, consultations, and teaching symposia is informed by our participation in collaborations bringing together four groups of experts at Washington University: the Teaching Center staff, researchers in the learning sciences, researchers in cognitive science, and faculty teaching in the disciplines. Each group brings a distinct area of expertise that is essential to a shared goal of improving teaching and learning. Staff at the Teaching Center-with $\mathrm{PhDs}$ in the sciences, the social sciences, and the humanities-bring expertise in SoTL and in designing, implementing, and assessing pedagogy across the disciplines. Learning scientists bring knowledge of 
Figure 3.1 Collaboration among Experts Leads to Continual Integration of Effective Pedagogical Practices and Research on Teaching and Learnings

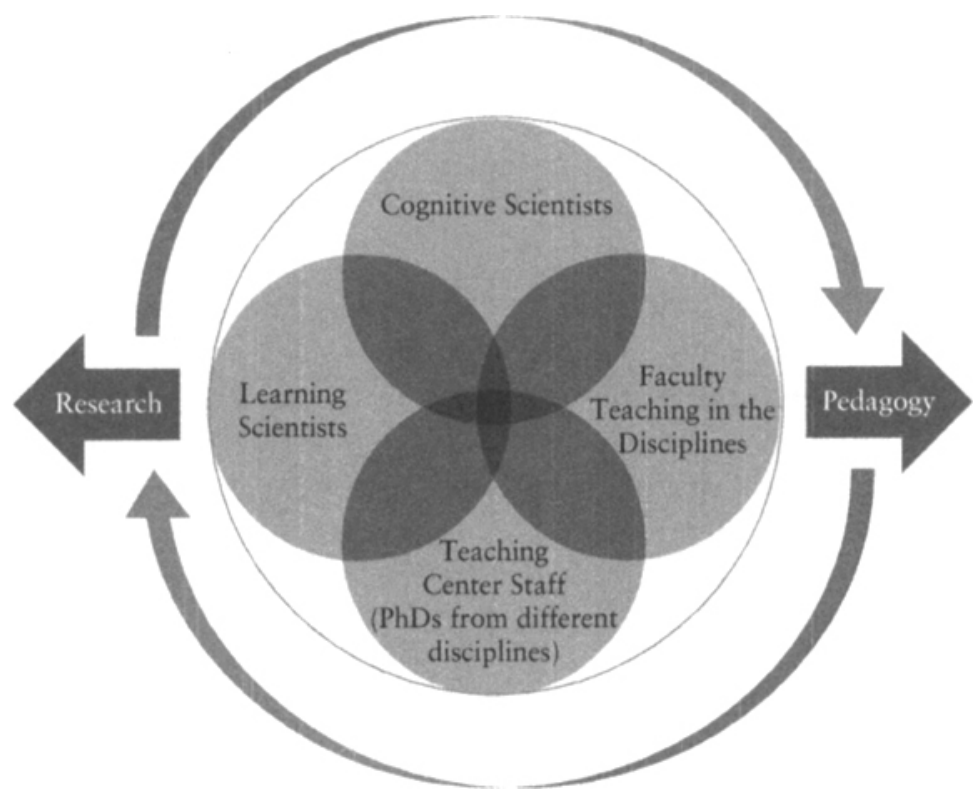

research on how to design and assess curricula and classrooms that promote learning. Cognitive scientists bring conceptual models of learning derived from experimental research in the laboratory. Faculty teaching in the disciplines bring knowledge of specific teaching and learning challenges, drawn from their experiences designing and teaching courses and from their knowledge of discipline-specific educational research and SoTL. Collaboration among these four groups takes shape in multiple configurations. The results include new research, as well as the refinement of effective pedagogical practices, as research on teaching and learning and the practice of teaching inspire and feed into one another, in a collaborative process that fosters a growth mind-set in all of us (figure 3.1).

The resulting collaborations, some of them research collaborations, typically involve two or more groups but can involve all four. For example, Regina Frey, the executive director of the Teaching Center, and Florence E. Moog, professor of STEM (science, technology, engineering, and mathematics) education, conduct educational research with collaborators from the learning sciences and cognitive science, as well as with faculty from different disciplines. These collaborations signal the 
emergence of a campus culture focused on integrating teaching and research. This culture can be seen in the 2008 founding of the Washington University STEM Education Research Group (ERG), in which faculty from STEM departments, including psychology, and the Department of Education meet weekly to discuss their educational research (Fisher \& Frey, 2011). This culture can also be seen in the 2011 creation of the Center for Integrative Research on Cognition, Learning, and Education (CIRCLE), which provides an additional structure for collaborative research involving cognitive scientists, discipline-education researchers, and faculty from across the disciplines. This center is codirected by Frey and professor of psychology Mark McDaniel.

The collaborative research of these four types of experts has also informed the Teaching Center's approach to working with faculty to design and assess instructional modifications that apply recent research on learning. Whether we are developing faculty workshops or working with faculty in individual consultations on teaching or on SoTL projects, we first identify specific challenges that faculty face when designing courses and curricula. These challenges may pertain to specific learning objectives for students, such as learning dense areas of new knowledge or building the critical-thinking skills needed to solve complex problems, build analytical arguments, and synthesize disparate facts and ideas into an original proposal.

The next step is multifaceted: we draw on our own knowledge of effective pedagogical practices as we investigate what recent research can tell us about how to improve student learning. This research includes classroom-based studies, drawn from relevant discipline-specific educational studies and from the learning sciences. Keith Sawyer, associate professor of education, who has conducted collaborative research with Frey, has been instrumental in defining the relatively new field of the learning sciences. Sawyer (2005) describes the learning sciences as an interdisciplinary field that brings together "researchers in psychology, education, computer science, and anthropology, among others" (p. 3). The "goal of the learning sciences is to better understand the cognitive and socio-cultural processes that result in the most effective learning, and to use this knowledge to redesign classrooms and other learning environments so that people learn more deeply and effectively" (Sawyer \& Nathan, in press). Working primarily with educators in $\mathrm{K}-12$ schools, learning scientists use an iterative design process that draws on current research on teaching and learning to redesign learning environments and assess how students learn in the redesigned environment (R. K. Sawyer, personal communication, November 12, 2012). 
We also incorporate recent cognitive science research. In this field, researchers develop models of how learning occurs based on carefully designed laboratory experiments. These experiments are not designed to replicate how learning occurs in the messy world of the classroom; they are designed to isolate and control for specific variables and study whether manipulating those variables has any effect on learning. However, over the past decade, cognitive scientists have become interested in bridging the gap between laboratory research and the real-world environment of the classroom (Mayer, 2008; Mestre \& Ross, 2011). Some have published reviews of current cognitive science research that suggests specific teaching and learning strategies that may improve learning outcomes (Dunlosky, Rawson, Marsh, Nathan, \& Willingham, 2013; Mayer, 2008; Pashler et al., 2007; Willingham, 2009). These researchers include faculty from our Department of Psychology, such as McDaniel, Kathleen McDermott, and Henry Roediger (McDaniel, Roediger, \& McDermott, 2007; Roediger, Agarwal, McDaniel, \& McDermott, 2011; Roediger, McDermott, \& McDaniel, 2011). Although much of the work integrating cognitive science with classroom practice is addressed to $\mathrm{K}-12$ educators, many cognitive scientists are conducting laboratory research that engages directly with learning in higher education (McDaniel, Anderson, Derbish, \& Morrisette, 2007). Cognitive scientists are also beginning to collaborate with higher education faculty to measure the effectiveness of instructional modifications that apply learning theory (M. McDaniel, personal communication, November 13, 2012; Mestre \& Ross, 2011).

There is clearly a need for faculty to work with faculty developers to learn about research on learning and use this knowledge to modify and improve their instructional methods; in addition, there is a need for researchers in cognitive science and the learning sciences to collaborate with faculty developers and faculty in order to better understand authentic teaching and learning challenges. Such collaboration is central to improving teaching and learning in higher education.

\section{"Show Me the Data": Disseminating Recent Research on Learning in Faculty Workshops}

Our faculty interact with the Teaching Center using multiple pathways, including workshops, consultations, teaching symposia, and research collaborations. Our most extensive teaching collaborations with faculty occur in workshops and consultations. In the workshops, typically sixty to ninety minutes long, we present research on learning and facilitate 
group discussion of the research and its implications for the participants' teaching. Because our staff have $\mathrm{PhDs}$ with teaching expertise in multiple disciplines, we can work as a team to identify research on learning, as well as specific instructional modifications that are flexible enough to be applied in courses of various sizes and in different disciplines. To promote a growth mind-set about teaching and learning, we begin workshops by presenting study details, such as participant demographics and study conditions (e.g. classroom or laboratory based, level of experimental control). In addition, we describe the study methods and present the relevant data or results. We have found that faculty are curious not only about the ideas that can be drawn out of research on learning; they are also curious about how this research is conducted. Discussing the study details helps faculty assess the significance of the data and its relevance for their teaching, as well as develop a better sense of how to read and understand research on learning when they embark on their own investigations of this research after the conclusion of the workshop.

When presenting study details, we strive to help faculty transform knowledge of recent research on learning into knowledge that they can adapt and modify as they refine their teaching over time. To accomplish this transformation, translating terminology is often crucial. For example, the terminology used in cognitive science literature may not be recognized as specialized language. In fact, there is a potential for misunderstanding precisely because cognitive scientists use terms that are widely used in education (e.g., study and test). However, in the cognitive science literature, these terms have more specific meanings than they do when educators use them more broadly. For instance, "to study" often means "to read," while "to test" often means to measure retention or transfer. (Retention tests measure how much knowledge a learner retains and can retrieve from memory; transfer tests measure how well a learner can apply newly learned knowledge to a novel situation.) Translating these terms by explaining their specific meanings within the primary literature is one of the most important aspects of our approach, and it represents one of the primary areas in which the cross-disciplinary knowledge of faculty developers can have a significant impact on efforts to disseminate research on learning to faculty across disciplines.

\section{Translating Research into Practice: Recommendations}

When developing and delivering workshops and working with faculty individually in consultations, we follow discussions of the selected studies with specific recommendations of instructional modifications informed by 
the studies. Our recommendations are designed to help faculty develop ideas for modifying their own teaching to improve learning. For example, several of our workshops have included discussion of laboratory-based experiments that have compared how college students performed on retention tests when they engaged in retrieval practice, that is, to recall information they had just read or heard, compared to students who reread the text one or more additional times but did not engage in retrieval practice before being tested (Karpicke \& Blunt, 2011; Lyle \& Crawford, 2011; Roediger \& Karpicke, 2006). The positive effects of retrieval practice have been shown not only in student performance on questions that require recall of factual information from a previously read text, but also on questions that ask students to make inferences based on facts presented in the text they have already read (Karpicke \& Blunt, 2011).

When we present these findings to faculty, we facilitate discussion of multiple strategies that suggest how retrieval practice and other concepts can be incorporated into teaching. For example, we describe strategies such as starting class with a low-stakes quiz or series of questions that prompt students to generate information they have just learned, or combining short lectures with group work designed to help students remember and apply what they have just learned in the lecture. We describe such strategies not as prescriptions but as flexible approaches that can be incorporated incrementally. In addition, we include specific logistical recommendations, stressing the importance, for example, of structuring group work by limiting groups to three to four students, giving clear instructions and time limits, and asking the groups to report and discuss the results of their work. This approach incorporates strategies drawn from education literature on classroom-assessment techniques and active learning (e.g., Angelo \& Cross, 1993; Eberlein et al., 2008). However, it takes these strategies in a new direction by helping faculty understand concepts from learning and memory research that they can use to ensure that these strategies help students build and retain new knowledge and skills. Understanding these concepts also helps faculty adapt these strategies for their own courses and students and devise plans for assessing and modifying these implementations over time.

\section{Preliminary Evaluation: Survey of Faculty Workshop Participants}

In 2012, we presented four faculty workshops entitled Applying Cognitive Science to Improve Teaching. Two of the workshops were for multidisciplinary faculty from arts and sciences, business, medicine, and engineering, 
and two were for medical faculty. We have also integrated information from research on learning into workshops on such topics as incorporating active learning, teaching with PowerPoint, and teaching with lectures.

In November 2012, we administered a survey to faculty who had participated in one of the faculty workshops on applying cognitive science research to improve teaching (the only participants not invited had attended a medical faculty workshop, for which attendance records were not available). We invited seventy-seven workshop participants to complete the survey, which asked respondents to indicate their perceptions of the usefulness of the workshop content and the extent to which the workshop increased their likelihood to incorporate specific instructional modifications based on the presented studies. The response rate was approximately 36 percent, with twenty-eight faculty members responding. The demographic representation of the survey respondents was similar to that of the seventy-seven survey invitees. Respondents came from sixteen departments, representing the humanities, social sciences, natural sciences, and medicine. A majority of the respondents (fifteen) had tenure-line faculty appointments at or above the level of assistant professor. Nearly two-thirds of the respondents were women.

The survey respondents found each of the major workshop components to be useful (figure 3.2). More specifically, when asked to rate the usefulness of the group discussions on how to apply the research findings to teaching, 69 percent responded "useful" or "very useful." When asked to rate the usefulness of "specific, detailed recommendations for applying cognitivescience findings to classroom teaching," 74 percent responded "useful" or "very useful." Nearly all ( 89 percent) reported that the "review and explanation of data from recent cognitive-science studies on learning and memory" was "useful" or "very useful." Respondents also reported increases in their likelihood to incorporate the recommended modifications: 82 percent reported being more likely to use active learning activities, and 59 percent reported being more likely to use weekly quizzes (figure 3.3).

The survey included open-ended questions about whether the participants had already incorporated the recommended modifications. Responses to these questions suggest several themes, as illustrated by the comments that follow:

I wanted to incorporate in-class group work, but received a fair amount of redirection from colleagues. But after this workshop, I was determined to figure it out. I had 3 in-class group assignments with 98 students, and they loved it! It worked out just as I had hoped. They retained the information through [the] active-learning activity rather 
Figure 3.2 Percentage of Survey Respondents Who Rated the Relative Usefulness of Each of the Major Workshop Components

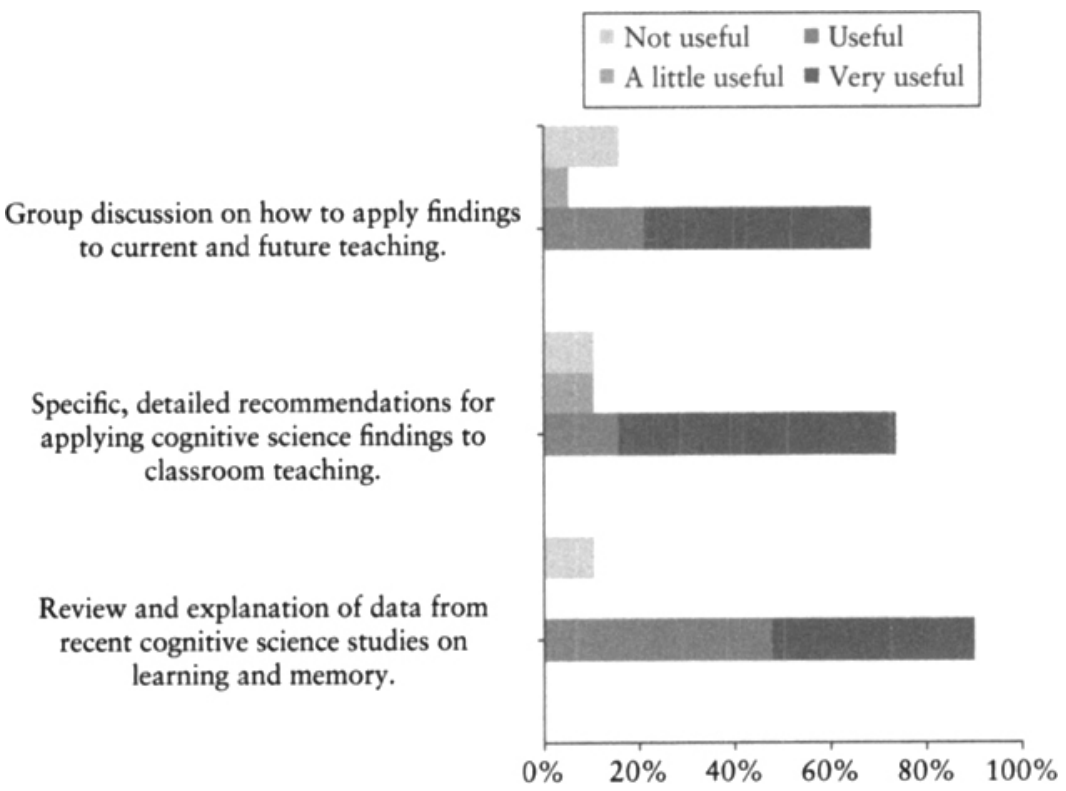

than [through my] lecturing with PowerPoint on how to develop and implement a study.

This semester, I will incorporate more of [the recommended strategies] in both lecture content and their homework assignments. Actually, taking this survey at this time is REALLY helpful as I am now redoing the syllabus for the spring semester and can make sure I incorporate some of the insights from this workshop.

I build in more active elements, including ungraded midsession quizzes to practice retrieval just minutes after material is presented. This seems to work well in that students do recall correct answers, and it generates conversation when there is confusion. I will continue to use this method.

I am now giving short quizzes to improve memory recall. I have active learning activities either in each class or at least every week. 1 would use the modifications again in my reaching.

When I first told the students that there would be in-class group work, they were not happy. I told them it would work out and it did. 
Figure 3.3 Percentage of Survey Respondents Indicating Whether Participating in the Workshops Made Them More Likely to Implement Pedagogical Modifications Recommended in the Workshops

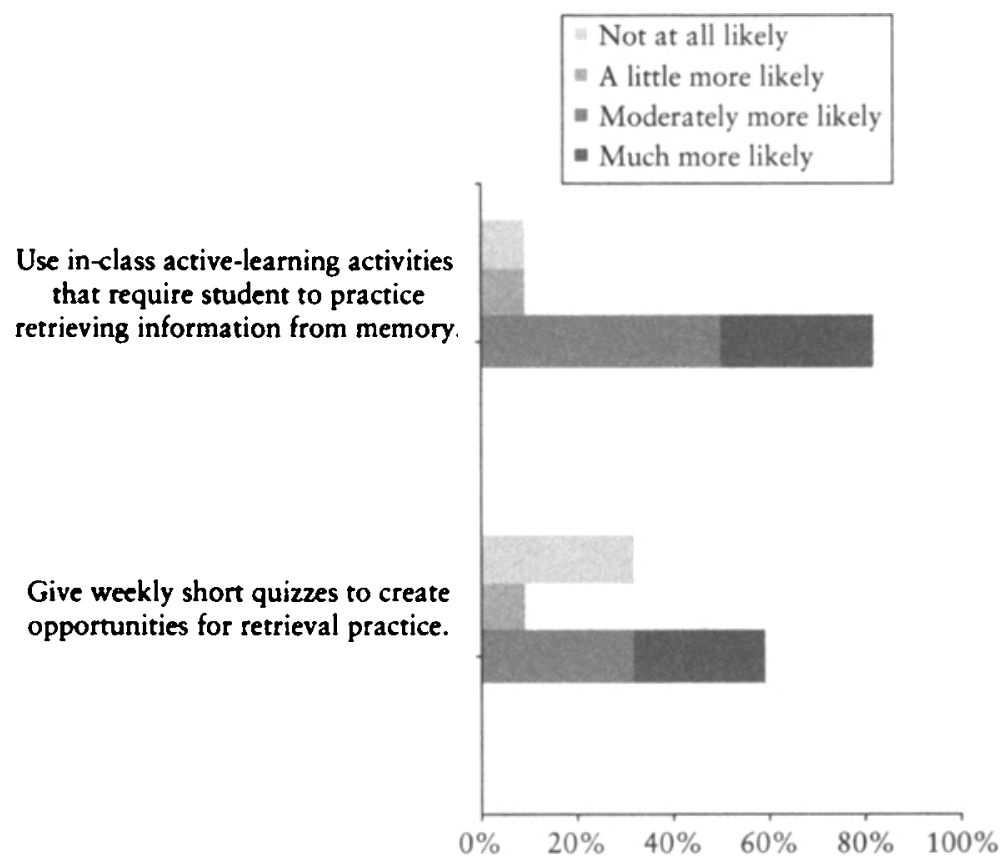

But I made sure to get the housekeeping and logistics all settled before I actually had them do an in-class group assignment. That meant getting them into small groups through sign-up sheets and emails, then setting up the lecture hall to facilitate their group seating arrangement.

First, the comments conveyed clear enthusiasm about incorporating the modifications, as well as appreciation for the provided guidance on the logistical aspects of how to incorporate these modifications.

Second, when asked about barriers they had encountered when incorporating-or attempting to incorporate-the recommended modifications, the respondents cited time constraints and resistance by students and colleagues. Notably, a few of the respondents said that taking an incremental approach to incorporating modifications, as well as sharing with students and colleagues the rationale behind the modifications, helped faculty to overcome these barriers. In addition, a quarter of the respondents reported that after participating in the workshops, 
they were "more likely to have informal discussions with colleagues about applying cognitive science to improve teaching." Several respondents also reported mentoring other faculty in this area, as well as working with co-instructors to adapt and implement the recommended modifications. In other words, the survey responses suggested that workshop participants had started to develop a growth mind-set about teaching and were becoming scholars of teaching and learning.

While the survey represents a preliminary evaluation of our workshops on applying research on learning, the results are encouraging. Most notably, they point to the increased likelihood of implementing instructional modifications integrating concepts from cognitive science and learning sciences research. In addition, they speak to the faculty's need for guidance on the logistical aspects of adapting these modifications incrementally and effectively. The results also suggest that faculty workshop participants are excited about continuing to incorporate, adapt, refine, and assess the concepts and strategies they learned in the workshops.

\section{"Practical, Hard-Nosed Advice": Consultations with Faculty}

Without specific, detailed recommendations for modifying their teaching, faculty might be intrigued by research on learning but remain unsure of how to apply this research in their own teaching. Therefore, they often need advice from centers for teaching and learning staff on how to devise a feasible plan for implementing and assessing modifications based on the research. At the Teaching Center, we provide such advice not only in workshops and symposia but also in individual faculty consultations. During consultations, we use a taxonomy of learning drawn from education theory (Anderson et al., 2001; Bloom, 1956) to help faculty members identify course goals and then determine how well the their current instructional approach aligns with these goals. Looking carefully at the faculty member's lecture notes and other materials, we discuss whether and how specific instructional modifications, informed by research on learning, could improve student learning in the course. In addition, we help the faculty member identify specific points at which retrieval practice or other modes of active learning could be incorporated into each class session.

Susan Fitzpatrick, who teaches neuroscience in the departments of anatomy and neurobiology and in the program in occupational therapy, has reflected on her experience with this process. As a result of her research expertise, as well as her work as vice president of the James $\mathrm{S}$. McDonnell Foundation, which supports research and scholarship in 
brain science and human cognition, Fitzpatrick has a high level of knowledge about cognitive science and its potential for improving teaching and learning. However, she notes that implementing pedagogical modifications based on cognitive science or other research on learning can be a daunting prospect for faculty. Furthermore, faculty are unlikely to implement their new knowledge of the research if they do not get practical advice on "what [they] can actually do." Describing her experience of redesigning her course to incorporate questions prompting students to use retrieval practice and incorporate more active learning exercises, Fitzpatrick notes that consultations with the Teaching Center's executive director provided her with "practical, hard-nosed advice" from someone who has been "on the ground"-an experienced instructor who brings expertise in teaching as well as knowledge about research on learning. Fitzpatrick appreciates that the recommendations are flexible, so implementing them does not mean faculty are "locked into a complex curriculum or system." Instead, they can implement modifications in a way that fits the individual instructor's discipline, course, teaching style, and students; in addition, an instructor can readily understand how to make additional modifications to fit each new course or group of students. The result is "a more dynamic, adaptable system . .. and therefore a more resilient classroom" (personal communication, November 19, 2012).

Consultation with the Teaching Center also enables the faculty member to create a plan for assessing the effectiveness of the planned modifications. Discussing and learning about how research on teaching and learning is conducted-whether in cognitive science, the learning sciences, or discipline-specific education research-helps faculty members think about how they can assess learning in their own courses. The assessment may begin informally with the faculty member's reflections on student work and student evaluations (or other feedback), or with observation and feedback by staff from the Teaching Center. Continued consultation can guide this process, which in some cases develops into a formal evaluation study or a SoTL project, designed in collaboration with either the Teaching Center or CIRCLE.

After laying the groundwork in workshops, consultations, or teaching symposia for faculty to think about how research on teaching and learning is conducted, we find that faculty are primed to think about how to design a study to assess learning in their own courses. Our discussions with them about research on learning not only give us a deeper sense of specific teaching and learning challenges and the extent to which current research on learning may suggest new ways to meet those challenges; these discussions also reveal areas of teaching and learning that the 
research has not yet examined-prompting ideas for new research. In other words, at the same time that research on learning can suggest new ways to invigorate teaching, our collaborative efforts to refine and improve teaching points to gaps in the research that can be addressed by new classroom- or laboratory-based studies.

\section{Recommendations}

The recommendations that follow for faculty developers who are engaged in efforts to help faculty learn about and apply research on teaching and learning highlight strategies that can foster a growth mind-set about teaching and lead faculty to become scholars of teaching and learning:

1. In workshops, consultations, and symposia or other programs that incorporate research on learning, help faculty understand the research study details, think conceptually about the results of this research, and consider how the results can be applied when developing and refining effective teaching practices.

o Present the study details, such as number of participants, study conditions (e.g. classroom or laboratory based; degree of experimental controls employed), methods, and results.

o Facilitate discussion of the study results and their potential for improving teaching and learning in specific disciplines.

o Be attuned to linguistic barriers that may make it difficult for faculty from different disciplines to understand the terminology employed by researchers from cognitive science or the learning sciences (e.g. study and test). Define terms when needed to promote mutual understanding of what the research does-and does notsuggest about how learning occurs and to clarify specific practices that instructors and students can use to maximize learning.

- Present specific, elaborated recommendations of instructional modifications that are applicable and feasible in different disciplines and courses. These recommendations should include suggestions on the logistical aspects of the implementations, how these modifications may be implemented incrementally, and ideas about how faculty can assess these modifications.

2. Expand your knowledge of research on teaching and learning from the learning sciences, cognitive science, and educational research in the disciplines.

o Read recent literature from all of these research areas and seek out opportunities to discuss this literature with colleagues from 
these fields. Your colleagues can help you determine the research areas that are most relevant to teaching and learning in higher education. We expect that they will be enthusiastic to talk with you, as will faculty in all other disciplines who are interested in discussing how this research might help them improve student learning in their courses.

- Seek out opportunities to develop collaborative research on teaching and learning with colleagues from your institution or elsewhere.

o Form research groups that bring together colleagues from all of the above areas to discuss their research on teaching and learning. Develop a structure that enables these groups to meet on a regular basis to present their research and to collaborate with one another, both formally and informally (Fisher \& Frey, 2011; Huber \& Hutchings, 2005).

3. Continue to refine your teaching expertise by modifying and assessing your own pedagogical methods-whether in courses or in the development of workshops, seminars, or other learning opportunities for faculty and graduate students. Learning about the research is only the first step. Developing pedagogical modifications that can work and be assessed in the classroom is often a more challenging step. Your expertise as an experienced educator will help you develop specific recommendations for modifying teaching that are not only informed by research but also designed in a way that can be readily adapted, implemented, and assessed by faculty teaching across disciplines. Continuing to teach will also allow you to develop logistical suggestions on how to implement these recommendations.

\section{Conclusion}

We intend this description of our approach to provide a broad philosophy, as well as concrete ideas and strategies, that others may adapt and modify as they expand and diversify their own efforts to improve teaching and learning by integrating research and pedagogy. The ultimate goal of our approach is to solidify what is beginning to emerge at our universitya collaborative culture in which scholars across disciplines understand research on teaching and learning and the practice of teaching as vibrant, evolving, mutually informing enterprises. The development of this culture is akin to the emergence of a space for multidisciplinary discussions about the scholarship of teaching and learning that Huber and Hutchings 
(2005) call the "teaching commons." We understand this culture of collaboration as just one manifestation of a broader movement toward integrating research and teaching-a movement that is advancing in multiple directions across many different institutions.

\section{REFERENCES}

2012 iteach offers faculty opportunity to exchange ideas on teaching. (2011, December 6). Record. Retrieved from http://news.wustl.edu/news/Pages 123074.aspx

Ambrose, S. A., Bridges, M. W., DiPietro, M., Lovett, M. C., \& Norman, M. K. (2010). How learning works: Seven research-based principles for smart teaching. San Francisco, CA: Jossey-Bass.

Anderson, L. W., Krathwohl, D. R., Airasian, P. W., Cruikshank, K. A., Mayer, R. E., Pintrich, P. R., Rath, J., \& Wittrock, M. C. (2001). A taxonomy for learning, teaching, and assessing: $A$ revision of Bloom's taxonomy of educational objectives. New York, NY: Longman.

Angelo, T. A. (1993). A "teacher's dozen": Fourteen general, research-based principles for improving higher learning in our classrooms. AAHE Bulletin, 45(8), 3-13.

Angelo, T. A., \& Cross, K. P. (1993). Classroom assessment techniques: A handbook for college teachers. San Francisco, CA: Jossey-Bass.

Bloom, B. (1956). Taxonomy of educational objectives: Vol. 1. Cognitive domain. New York, NY: McKay.

Bransford, J., Brown, A. L., \& Cocking, R. R. (Eds.). (2000). How people learn: Brain, mind, experience, and school. Washington, DC: National Academy Press.

Dunlosky, J., Rawson, K. A., Marsh, E. J., Nathan, M. J., \& Willingham, D. T. (2013). Improving students' learning with effective learning techniques: Promising directions from cognitive and educational psychology. Psychological Science in the Public Interest, 14(1), 4-58. doi:10.1177 /1529100612453266

Dweck, C. S. (2006). Mind-set: The new psychology of success. New York, NY: Ballantine Books.

Eberlein, T., Kampmeier, J., Minderhout, V., Moog, R. S., Platt, T., VarmaNelson, P., \& White, H. B. (2008). Pedagogies of engagement in science. Biochemistry and Molecular Biology Education, 36(4), 262-273. doi:10.1002/bmb.20204

Fisher, B. A., Miller, K. G., Buhro, W. E., Frank, D. J., \& Frey, R. F. (2012). Collaborating with faculty to design active learning with flexible technology. In J. E. Groccia \& L. Cruz (Eds.), To improve the academy: Resources 
for faculty, instructional, and organizational development, Vol. 31 (pp. 329-346). San Francisco, CA: Jossey-Bass/Anker.

Fisher, B. A., \& Frey, R. F. (2011). Adapting a laboratory research group model to foster the scholarship of teaching and learning. In J. E. Miller \& J. E. Groccia (Eds.), To improve the academy: Resources for faculty, instructional, and organizational development, Vol. 30 (pp. 99-111). San Francisco, CA: Jossey-Bass/Anker.

Huber, M. T., \& Hutchings, P. (2005). The advancement of learning: Building the teaching commons. San Francisco, CA: Carnegie Foundation for the Advancement of Teaching and Jossey-Bass.

Karpicke, J. D., \& Blunt, J. R. (2011). Retrieval practice produces more learning than elaborative studying with concept mapping. Science, 331(6018), 772775.

Lyle, K. B., \& Crawford, N. A. (2011). Retrieving essential material at the end of lectures improves performance on statistics exams. Teaching of Psychology, 38(2), 94-97. doi:10.1177/0098628311401587

Mayer, R. E. (2008). Applying the science of learning: Evidence-based principles for the design of multimedia instruction. American Psychologist, 63(8), 760-769.

McDaniel, M. A., Anderson, J. L., Derbish, M. H., \& Morrisette, N. (2007). Testing the testing effect in the classroom. European Journal of Cognitive Psychology, 19(4-5), 494-513.

McDaniel, M., Roediger, H., \& McDermott, K. (2007). Generalizing testenhanced learning from the laboratory to the classroom. Psychonomic Bulletin and Review, 14(2), 200-206.

Mestre, J., \& Ross, B. H. (Eds.). (2011). Cognition in education. San Diego, CA: Academic Press.

Pashler, H., Bain, P. M., Bottge, B. A., Graesser, A., Koedinger, K., McDaniel, M., \& Metcalfe, J. (2007). Organizing instruction and study to improve student learning. IES practice guide. Washington, DC: National Center for Educational Research, Institute of Education Sciences, US Department of Education.

Roediger, H. L., Agarwal, P. K., McDaniel, M. A., \& McDermott, K. B. (2011). Test-enhanced learning in the classroom: Long-term improvements from quizzing. Journal of Experimental Psychology: Applied, 17(4), 382-395. doi:10.1037/a0026252

Roediger, H. L., \& Karpicke, J. D. (2006). Test-enhanced learning. Psychological Science, 17(3), 249-255.

Roediger, H. L., McDermott, K., \& McDaniel, M. A. (2011). Using testing to improve learning and memory. In M. A. Gernsbacher, R. Pew, L. Hough, \& J. R. Pomerantz (Eds.), Psychology and the real world: Essays illustrating 
fundamental contributions to society (pp. 65-74). New York, NY: Worth Publishers.

Sawyer, R. K. (2005). Introduction: The new science of learning. In R. K. Sawyer (Ed.), Cambridge handbook of the learning sciences (pp. 1-16). Cambridge: Cambridge University Press.

Sawyer, R. K., \& Nathan, M. J. (in press). Teaching and the learning sciences. In D. Gitomer \& C. Bell (Eds.), Handbook of research on teaching (5th ed.). Washington, DC: American Educational Research Association.

Willingham, D. T. (2009). Why don't students like school? A cognitive scientist answers questions about how the mind works and what it means for your classroom. San Francisco, CA: Jossey-Bass. 